diphtheria, never put in an appearauce. More than all, hausting air from the lungs, would prove a very dangerI have yet to see a case of paralysis of even the soft palate ous instrument to place in the hands of the average phyfollow diphtheria when this treatment has been adhered sician in an emergency case.

to from the beginning. When called to see a diphtheria However, no one will question that Richardson, patient, in addition to above treatment I give to other Hunter, the designer of the apparatus mentioned in Dr. children of the family that have been exposed to con- Herzog's letter, and several otbers whom I could cite, tagion, from one to four (according to age) one-tenth have prepared or invented instruments for forced tespiragtain calomel pills every five hours for two or three days tion upon human beings.

as a preventive, with uniform success, a large majority With all their labor, what did they accomplish? Was thus treated escaping the disease or suffering only a light a single human life saved by them? Did they demontouch of it, the germicide entirely protecting those parts strate the wonderful possibilities of the method? Let us usually affected by diphtheria.

Do not be afraid of the calomel. The verge of ptyalism must be reached in order to secure the best results.

see. After my first operation with the instrument used in my physiological laboratory, and with which, notwithstanding its defects or adaptation for the purpose, I

We do not fear salivation now as we did when I first had succeeded in keeping my patient alive for nearly began the practice of medicine, over fifty years ago. At three hours, until he breathed for himself, I looked up that time we could not control it; now, with chlorate of the home and foreigu literature on the subject. Nothpotash, we regulate it with absolute certainty.

ing was discovered which appeared to controvert the fact,

If medical gentlemen who have the opportunity of that I was justly entitled to the credit of being the first making post-mortems upon patients having died of diph- to systematically and practically solve the question of theria will thoroughly investigate the changes that have taken place in the eighth pair of nerves, and, if it presents the appearances which I believe it will, my theory will be perfectly established, at least in my own mind, and I shall feel greatly indebted to them if they will report the same to me or to THE JOURNAL of the Association. DR. W. R. MCMAHON.

No. 3 I 2 South Front street, Mankato, Minn.

\section{Forced Respiration. Letter from Dr. Fell.}

To the Editor:-Your correspondent, Dr. Herzog, of Hoboken, N. J., leads me to believe from the tenor of his article on "Forced Respiration," in the May 9th number of THE JOURNAL, that he has not read my address upon this subject with that care which it deserved. Had he done so, I am inclined to believe that so much of the valuable space of THE JOURNAI, would not have been given to the elaborate account of an instrument which undoubtedly was never used to save human life; or, if it had been, it would likely have failed ingloriously. I will not now be surprised if some one should add that Hippocrates had thought of forced respiration, and even devised an apparatus to perform it with. John Hunter did both, and possibly others, but we have no record of any of these noted men having applied their invention to the saving of human life. See Prof. Horatio C. Wood's remarks in his address before the Berlin Congress, in which he says: "but I have not found that either Hunter or Richardson treated by forced artificial respiration, an actual case of disease or poisoning."

In all this apparatus a grave defect existed, in my opinion, in that provision was made to exhaust the air from the lungs; this complicates the apparatus, and, furthermore, is not in accord with physiological conditions, as inspiration is a forcible measure, while expiration, being passive and produced by the elasticity of the fibro-elastic tissue of the lungs, does not call for the utilization of mechanical means to produce it. I also believe that an apparatus provided with means for ex- the value of forced respiration in the saving of human life; or that I luad demonstrated, as one physician puts it, "that air can be forced into the lungs without any damage to them." Whatever has been accomplished, also should be stated, was without any previous knowledge of the failures in the same field, which had antedated my efforts.

I can say, with the practical knowledge obtained from operating upon human beings, that the instruments used in the physiological laboratory do not meet the conditions to be successfully overcome in breathing for a human being for any length of time. They may answer in some instances as a make shift, but the work is carried on at a great disadvantage, and with many cbances in favor of producing, instead of averting, a fatal result. They were never intended to be used upon human beings. The instrument originally devised by myself in all its practical details, and with which the results tersely detailed at the end of this letter were accomplished, was founded upon the experience obtained in my first case, and the results of my labor with it so over-whelmingly anuihilates any controversy in opposition to its use, that it is needless to do more than present them to the profession. Had similar results or demonstrations been accomplished at the hands of others in the past, nothing could have prevented them from receiving the widest publicity in the medical literature of the day, but no record is found which detracts from the practical value and originality of my labors. As a physiologist, I was acquainted with the apparatus used in the physiological laboratory, from the simple bellows with nozzle poked into the trachea of a $\mathrm{dog}$, to the more complicated constant Sprengle blower with interruptor, which admittedly would be of no use as an emergency instrument.

The apparatus I have used meets all requirements for forced respiration in man, with or without tracheotomy, and in the simplest manner. It covers all the methods which can be utilized in the operation, is adapted to be used out of doors or in a cold atmospliere, but may be modified by an arrangement to provide a constant air supply and automatic inspirator, which would, however, 
increase the cost, and do away with the emergency feature of the apparatus, as now used.

Dr. Herzog's article, possibly without intent, would naturally lead to the inference that the subject is old, not worth considering; its tenor is not uncertain. The truth is that the work in forced respiration, prior to my own, and running through the past century to a great extent, had simply relegated it to the list of unjustifiable procedures. Do we find anything previous based upon results recommending us to use forced respiration after all other methods of artificial respiration had failed? On the contrary, we do find in every medical work treating on the subject, the "Ready Method in Asphyxia of Marshall Hall," the highest accepted authority, that we must avoid the use of bellow's or any forcing instrument.

Now I propose to talk plain, as it seems entirely unnecessary at this late date to mince words upon this subject. The practical introduction to the world of the value of forced respiration in the saving of human life, the demonstrations which indicated its great possibilities, must be accredited to an American, and the work of others in the past had nothing to do with the results which were original in conception and practical application.

The question simply amounts to the difference between failure and stuccess; will the credit be accorded to those who failed or the one whosucceeded? If Columbus had prepared his ships, but not sailed across the Atlantic, would he have discovered America?

What also must be admitted by those who are inclined to accord justice to whom it is due, is that the practice of vivisection in the colleges and laboratories of the land, had no relation whatever to the saving of human life, or had it been ever taught in medical institutions, systematically or otherwise, as of any value in saving human life. For over eight years prior to my first operation of forced respiration upon a human being I had been a practical vivisectionist in the physiological laboratory, and during that time I never heard it even binted that a human life might be saved by the laboratory methods.

It was in the field of paralysis of the respiratory centres from opium that $I$ began my work with forced respiration and the demonstrations as to its efficacy, from the first, could not be questioned. Each and every case saved liad passed beyond the limit of hope so far as all known and systematically applied methods of resuscitation were concerned. To be denied the credit which should in all fairness be accorded to the practical originator of a method of such far reaching importance in the saving of human life is what I could not quietly submit to. "Honor to whom honor is due."

RÉSUMÉ OF CASES OF FORCED RESPIRATION TO DATE.

Case I.-Buffalo, N. Y., adult, morph. sulph., 20 grains taken. Artificial respiration and antidotes had failed. Case given up as hopeless. Dilatation of pupils, last stage of asphyxia taken place. Forced respiration for two and owe-half hours, with difficulty on account of incomplete apparatus, saved patient.

Case 2.-Prof. Dr. Boehm, Vienna, Austria. Two months later, and after Case I bad been fully reported to the Medical Congress at Washington, and published by the public press. Adult. Nearly 8 grains morph. sulph. taken. Artificial respiration failed and forced respiration saved the life of the patient.

In these two cases the methods used in the physiological laboratory were applied.

Case 3.--(Dr. Fell's 2nd Case), adult. Tr. opii. Zुi taken, all absorbed. Artificial respiration, antidotes, pushed to utmost, but they failed. With my new apparatus adapted to forced respiration on man, this patient was kept alive for fourteen hours before he could breathe for himself, and made a good recovery.

With the laboratory apparatus as used in my first case I could not have saved the patient.

Case 4.-Dr. Fell, Buffalo, N. Y. Adult. 'Tr. opii. そ3ii, taken. Anterior jugular vein and trachea severed by a razor. Hæmorrhage very profuse, patient almost exsanguinated. A corps of hospital physicians had given up the case. The coroner and undertaker even on hand with a coffin. At 5 o'clock P.M., I began breathing for the patient by forced respiration. 9 P.M., patient first conscious; 4 A.M., case considered hopeless; intravenous injection of salt solution $\zeta \mathrm{vi}$; IO A.M., patient improved. At I :3O P.M., or twenty-one and one-half hours from the time forced respiration was first instituted, the patient was left for a short time to breathe for himself. Becoming tired he requested the renewal of the forced respiration so that fully one whole day was used in forced respiration before auto respiration was thoroughly reëstab-

lished. This gentleman is now living in good health at Wheeiing, W. Va.

A few months after this my third case, these three gentlemen whose lives had been saved by my labors voluntarily appeared at my request before a section of the New York State Medical Association at Buffalo.

Case 5--Dr. Fell, Buffalo, N. Y. Adult, so years of age. Tr. opii. 3 i taken. Forced respiration kept patient alive twelve and one-half hours after he had been given up by a hospital staft:

Case 6.-Dr. Feli, Buffalo, N. Y. Infant only 18 days old. Morph. sulph. I gr. given by mistake of a homœpathic physician.

Five hours after this large amount, equivalent to about eighty doses, forced respiration per tracheotomy kept the clild alive nearly five hours. The results in this case were startling in the manifestations produced.

Case 7.-Dr. Fell, Buffalo, N. Y. Morphia in large but unknown quantity taken. Operation of tracheotomy undertaken after the pulse at both wrists lost; dilatation of asphyxia had taken place; auscultation failed to detect heart action; blood venous on tracheotomy. Forced respiration produced the return of the pulse at both wrists, and clear action of the heart on ausculation; blood became arterial; heart ceased beating in about one hour.

Case 8.-Dr. Fell, Buffalo, N. Y. Still born infant. Compression of brain prevented forced respiration from proving successful.

Operation suspended before heart ceased beating.

Case 9.-Dr. Fell, Buffalo, N. Y. Adult. Tr. opii, 2 ounces taken. Face mask held life until tracheotomy 
made. Eleven hours of forced respiration saved patient. Case 10.-Dr. Fell, Buffalo, N. X. Adult. Morphia, 5 grains to Io, and tr. opii, 2 ounces taken. Forced respiration for fourteen hours saved patient.

Case 11.-Dr. Fell, Buffalo, N. Y. Young woman had taken I or 2 ounces tr. opii. Forced respiration for four hours with face mask saved patient.

Cases 12, 13, 17.-Dr. C. R. Vanderburgh, Columbus, Ohio. Three cases, face mask used. Forced respiration for two to four hours saved patients.

Case 15.-Dr. Fell, Buffalo, N. Y. Adult female. Morph. sulph. in large quantities taken. Forced respiration for seven hours kept patient alive, where Sylvester's method of artificial respiration in the hands of another physician signally failed to prevent returning cyanosis. Forced respiration with face mask quickly overcome it, but was given up for Faradayism which resulted fatally. Forced respiration would have saved this case.

Case 16.-Hospital case reported as saved by the Fell method. Particulars not obtained.

Case I7.-Dr. Fell, Buffalo, N. Y. Young lady medical student took 15 grains of morphia. Forced respiration with face mask for three hours, and per tracheotomy for about ten saved her life.

During this case auscultation failed to detect heart action and pulse at wrist was absent for a time.

Case 18.-Dr. Fell, Buffalo, N. Y. Adult. Over doses of phenacetin, morphine and cocaine taken accidentally. Forced respiration for eleven hours with the face mask, and per tracheotomy for about seven, failed to save life. Dr. Fell was absent some time before death took place.

Oxygen gas was used in connection with the apparatus with good results in these last two cases.

Case 19.- The value of forced respiration as a tidingover measure in various conditions was exemplified in the following case. An old lady, seventy-three years of age, had taken, through the careless of a druggist, a dose of aqueous solution of corrosive sublimate. It resulted in producing a condition of shock; cyanosis was supervening, and death, which was inevitable, would have soon ensued. Forced respiration with the face mask easily applied, toned up the system so that respiration was much improved, and the patient lived about two days longer for the treatment.

Oxygen gas in this case, probably at too late a period, had no influence on the case.

I have received indefinite reports of cases occurring at other points which I am unable to report at this time. The record is sufficiently full to indicate the wonderful results of the method.

As the necessity has arisen by which the successful methods in forced respiration may be distinguished from those which are obsolete or impracticable and have resulted in casting a ban upon a most valuable operation by which, when properly applied, many human lives may be saved, I suggest that my method be known as the Fell method of forced respiration. Briefly it covers the method per tracheotomy, face mask or intubation tube, with the regularly intervaled respiratory movements indicated by the bellows, and controlled by the air valve in the hands of the surgeon; or the use of the bellows and other factors without the intervention of the air valve. Very respectfully,

72 Niagara St., Buffalo, N. Y

\section{BOOK REVIEWS.}

Medico-Chirurgical Societry of Glasgow. Discussion on ANesthetics. Edited by J. WALKER DoWNIE, M.B., F.F.P. and S.G., Secretary. Glasgow ; 1891. pp. I36.

This little book is a reprint from the Glasgow Medical Journal of a discussion on the subject of Anæsthetics which took place at three successive meetings of the Medico-Chirurgical Society of Glasgow, held respectively October $\mathrm{I} 7,24$ and $3 \mathrm{I}, \mathrm{I} 890$. There is an introduction by Dr. Wi1liam Macewen, and papers as follows: "The Action of Anæsthetics on the Respiration and Cardiac Action, and on the Risks Incident to this Action," by Dr. Joseph Coats; "On the Relative Value of the Various Anæsthetics," by Dr. T. Brown Henderson; "Ether as an Anæsthetic," by Dr. Hartley, of Leeds ; "On Primary Chloroform Syncope," by Dr. Robert Kirk ; "Thirty-five Years Experience of Anæsthetics," by Sir George MacLeod; "Anæsthetics in Relation to Midwifery," by Dr. William L. Reid; "Anæsthetics in Dental Practice," by Dr. Woodburn; "Nitrous Oxide, Cocaine and other Anæsthetics," by Dr. W. J. Fleming; "Causes of Death Under Chloroform," by Dr. Beatson ; "On Various Anæsthetics, with Special Reference to Methylene," by Dr. G. A. Turner ; "The Chemical Aspects of Anæsthetics," by Dr. George Buchanan ; "Experimental Observations and Inferences Relating to the Physiological Action of an Overdose of an Anæsthetic," . . . . . "Indications of Danger in Chloroform Narcosis," by Dr. David Newman; "The Administrations and Dangers of Anæsthetics," by Dr. James Dunlop; "Special Remarks on Ether," by Mr. H. E. Clark ; "Anæsthetics in Diseases of the Heart," by Dr. Alex. Robertson ; "Anæsthetics at the Children's Hospital," by Dr. Ness ; "Anæsthetics in Practice," by Dr. Walker Downie; "Anæsthetics in Obstetric Practice," by Dr. Samuel Sloan. Besides the formal papers above mentioned, there are brief discussions by Dr. Murdoch Cameron, Dr. Renton, Dr. Hector Cameron, Dr. McConville, Dr. Carmichael, Dr. McGregor Robinson, Dr. Stirton, Dr. Lapraik and the president of the society, Dr. William Macewen. The society has shown a commendable desire to avoid redundancy in both the papers and the discussions, and their conciseness adds to their value. The results of the Hyderbad Commission are sustained, and in conclusion, Dr. Macewen gives the most cogent reasons for his adherence to chloroform, and while he clearly states his preference, is undoubtedly fair to the adherents of ether. He gives a statement of the dangers of ether in its after-results, in which bronchitis and pneumonia are mentioned. $\mathrm{He}$ 